\title{
Implementation of a management guideline aimed at minimizing the severity of primary graft dysfunction after lung transplant
}

\author{
Judy Currey, PhD, RN, ${ }^{\mathrm{a}, \mathrm{b}}$ David V. Pilcher, MD, ${ }^{\mathrm{b}}$ Andrew Davies, MD, ${ }^{\mathrm{b}}$ Carlos Scheinkestel, MD, \\ Mari Botti, PhD, RN, ${ }^{a}$ Michael Bailey, PhD, MSc, BSc, ${ }^{\mathrm{d}}$ and Greg Snell, $\mathrm{MD}^{\mathrm{c}}$
}

\begin{abstract}
Objective: Primary graft dysfunction, a severe form of lung injury that occurs in the first 72 hours after lung transplant, is associated with morbidity and mortality. We sought to assess the impact of an evidence-based guideline as a protocol for respiratory and hemodynamic management.
\end{abstract}

\begin{abstract}
Methods: Preoperative and postoperative data for patients treated per the guideline $(n=56)$ were compared with those of a historical control group $(\mathrm{n}=53)$. Patient data such as ratio of arterial $\mathrm{Po}_{2}$ to inspired oxygen fraction, central venous pressure, cumulative fluid balance, vasopressor dose, and serum urea and creatinine were measured and documented at specific times. Primary outcome was severity of primary graft dysfunction within the first 72 hours.
\end{abstract}

Results: Primary graft dysfunction grade was progressively lower in patients treated after introduction of the guideline $(P=.01)$. Lower postoperative fluid balances $(P=.01)$ and vasopressor doses $(P=.007)$ were seen, with no associated renal dysfunction. There were no differences in duration of mechanical ventilation or mortality. Nonadherence to the guideline occurred in 10 cases $(18 \%)$.

Conclusions: Implementation of an evidence-based guideline for managing respiratory and hemodynamic status is feasible and safe and was associated with reduction in severity of primary graft dysfunction. Further studies are required to determine whether such a guideline would lead to a consistent reduction in severity of primary graft dysfunction at other institutions. Creation of a protocol for postoperative care provides a template for further studies of novel therapies or management strategies for primary graft dysfunction. (J Thorac Cardiovasc Surg 2010;139:154-61)

With some similarities to the adult respiratory distress syndrome in nontransplant settings, primary graft dysfunction (PGD) is a severe form of acute lung injury that develops in the first 72 hours after lung transplant and is associated with significant early and late morbidity and mortality. ${ }^{1,2}$ Published consensus criteria for defining and classifying the severity of PGD according to the ratio of recipient arterial $\mathrm{Po}_{2}\left(\mathrm{PO}_{2}\right)$ to fraction of inspired oxygen $\left(\mathrm{FiO}_{2}\right)$ and chest radiographic findings (Table 1$)^{3}$ offer the opportunity for uniform identification of PGD. Further refinements recently advocated by Oto and colleagues ${ }^{4}$ may further enhance the reliability and grading of current PGD criteria and assist in earlier identification and management of PGD in the intensive care unit (ICU).

\footnotetext{
$\overline{\text { From the Faculty }}$ of Health, Medicine, Nursing and Behavioural Sciences, ${ }^{a}$ Deakin University, Burwood, Victoria, Australia; the Department of Intensive Care Medicine $^{\mathrm{b}}$ and the Lung Transplant Service, ${ }^{\mathrm{c}}$ The Alfred Hospital, Melbourne, Victoria, Australia; and the Australian \& New Zealand Intensive Care Research Centre, ${ }^{d}$ Department of Epidemiology \& Preventive Medicine, Monash University, Alfred Hospital, Melbourne, Victoria, Australia.

Supported by The Alfred Research Trusts Small Project Grant T 10518.

Received for publication Dec 16, 2008; revisions received July 14, 2009; accepted for publication Aug 9, 2009.

Address for reprints: Judy Currey, PhD, RN, Faculty of Health, Medicine, Nursing and Behavioural Sciences, Deakin University, 221 Burwood Hwy, Burwood 3125, Victoria, Australia (E-mail: judy.currey@deakin.edu.au).

$0022-5223 / \$ 36.00$

Copyright (c) 2010 by The American Association for Thoracic Surgery doi:10.1016/j.jtcvs.2009.08.031
}

After noting that lung protective strategies with low tidal volume ventilation improve outcomes in patients with adult respiratory distress syndrome, ${ }^{5}$ we postulated that a similar approach might be beneficial for severe PGD. Indeed, it has been recommended that protective mechanical ventilation strategies should be instituted in the postoperative management of patients with PGD. ${ }^{6}$ In addition, because central venous pressure (CVP) greater than $7 \mathrm{~mm} \mathrm{Hg}$ has been shown to correlate positively with increased duration of mechanical ventilation and mortality after lung transplant, ${ }^{7}$ it seemed apparent that therapy aimed at maintaining the CVP at or below $7 \mathrm{~mm} \mathrm{Hg}$ (such as fluid restriction) might improve outcomes. On the basis of these principles, a guideline for the postoperative hemodynamic and respiratory management of all lung transplant recipients was developed. Our hypothesis was that the implementation of such a guideline might be associated with improved outcomes. We sought to assess the guideline's effect by prospectively studying patients managed after the implementation of the guideline and comparing their outcomes with those of a cohort of historical control patients. The purpose of this article is to report changes in outcomes that occurred after the guideline's implementation.

\section{MATERIALS AND METHODS}

\section{Guideline Development and Implementation}

The guideline was developed during early 2005 and introduced into clinical practice in October 2005. Its implementation was supported with 


\section{Abbreviations and Acronyms \\ $\mathrm{CVP}=$ central venous pressure \\ $\mathrm{FiO}_{2}=$ fraction of inspired oxygen \\ ICU $=$ intensive care unit \\ $\mathrm{PaO}_{2}=$ arterial $\mathrm{PO}_{2}$ \\ $\mathrm{PGD}=$ primary graft dysfunction}

medical and nursing education in the form of lectures and bedside advice. The 56 patients with lung transplants ( 42 double and 14 single transplants) managed after the introduction of the guideline until the planned completion of the study in January 2007 comprised the intervention group. One patient was excluded from the study because of admission to the ICU with extracorporeal membrane oxygenation. The historical control group consisted of all patients receiving lung transplants between March 2004 and September 2005, comprising 53 patients (43 double and 10 single transplants). Standardization of lung recovery techniques with antegrade and retrograde preservation with Perfadex (Vitrolife, Göteborg, Sweden) was introduced in March 2004 for all patients. Transplant techniques followed standard surgical practice. ${ }^{8-10}$ The study was approved by the human research and ethics committees of The Alfred Hospital and Deakin University.

The guideline is shown in Figures 1 and 2. Clinicians were directed to measure the $\mathrm{PaO}_{2} / \mathrm{FiO}_{2}$ ratio and cardiovascular parameters at specific times after admission to the ICU $(0,3,6,12,24,48$, and 72 hours) and more frequently if clinically indicated. Respiratory management was then stratified according to the $\mathrm{PaO}_{2} / \mathrm{FiO}_{2}$ ratio, with the aim of providing protective ventilation or weaning the patient from mechanical ventilation as appropriate. Cardiovascular management was aimed at maintaining adequate cardiac index and blood pressure, with a CVP $7 \mathrm{~mm} \mathrm{Hg}$ or lower if possible. When $\mathrm{PaO}_{2} / \mathrm{FiO}_{2}$ ratio was greater than 300 and both cardiac index and blood pressure were adequate, the goal of maintaining a low CVP was no longer pursued aggressively. The guideline not only served as a protocol care of the more stable patients but also specified thresholds at which nursing staff and junior medical staff should seek more senior help.

\section{Other Aspects of Management}

Other aspects of management remained unchanged, included donor assessment, recipient selection, donor-recipient matching, and postoperative medical management. The Alfred Hospital's approach to lung donor referral, assessment, and general management has been described elsewhere. ${ }^{9}$ Recipient selection is based on international guidelines. ${ }^{11}$ Donor-recipient matching was generally undertaken according to our standard protocol, which has also been described previously. ${ }^{8}$ Prospective donor-recipient T- and B-cell lymphocytotoxic crossmatching was performed in all cases. There were no changes in assessment or selection criteria during the study period. Postoperative triple immunosuppression was achieved and acute rejection was diagnosed and treated according to standard protocols and practice. ${ }^{8,9,12}$ All patients received prophylactic antibiotics on the basis of known or suspected donor and recipient microbiologic results. Ganciclovir was used as prophylaxis against cytomegalovirus as indicated. Immunosuppressive regimens and antibiotic and antiviral prophylaxis regimens did not change during the study period. None of the medical or surgical management practices were consciously altered during the period examined.

\section{Outcomes}

The severity of PGD (stratified into 3 groups of grades 0 and 1, grade 2, and grade 3) within the first 72 hours was the primary outcome. Patients were assigned PGD grades according to the consensus guidelines issued by the International Society for Heart \& Lung Transplantation Working Group. ${ }^{3}$ We did not analyze chest radiographs for the presence or absence of infiltrates when defining grades of PGD, because we previously noted
TABLE 1. Criteria for grading severity of primary graft dysfunction ${ }^{3}$

\begin{tabular}{ll}
\hline Grade & Criteria \\
\hline 0 & $\mathrm{PaO}_{2} / \mathrm{FiO}_{2}>300$ with no pulmonary infiltrates on chest \\
radiography \\
Extubated with $\mathrm{FiO}_{2}<30 \%$ or nasal cannulas \\
& Extubated with no pulmonary infiltrate on chest radiography, \\
& irrespective of $\mathrm{PaO}_{2} / \mathrm{FiO}_{2}$ \\
& $\mathrm{PaO}_{2} / \mathrm{FiO}_{2}>300$ with pulmonary infiltrates on chest radiography \\
& $\mathrm{PaO}_{2} / \mathrm{FiO}_{2} 200-300$ \\
& $\mathrm{PaO}_{2} / \mathrm{FiO}_{2}<200$ \\
3 & $\mathrm{Requirement} \mathrm{for} \mathrm{mechanical} \mathrm{ventilation,} \mathrm{nitric} \mathrm{oxide,} \mathrm{and} \mathrm{FiO}_{2}$ \\
& $>50 \%$ beyond $48 \mathrm{~h}$ \\
& Requirement for extracorporeal membrane oxygenation \\
&
\end{tabular}

$\mathrm{PaO}_{2}$, Arterial $\mathrm{PO}_{2} ; \mathrm{FiO}_{2}$, inspired oxygen fraction.

that this practice does not significantly affect the grading proportions. ${ }^{4}$ PGD grades 0 and $1\left(\mathrm{PaO}_{2} / \mathrm{FiO}_{2}\right.$ ratio $\left.>300\right)$ were analyzed as a single group. Secondary outcomes included duration of mechanical ventilation, ICU stay, use of inhaled nitric oxide, vasopressor (norepinephrine) dose, fluid balance during the first 72 hours, renal function (urea and creatinine on postoperative days 3 and 7), in-ICU mortality, in-hospital mortality, and ICU readmission rates. Nonadherence to the guideline was assessed according to 3 predefined criteria (lack of documentation of $\mathrm{PaO}_{2} / \mathrm{FiO}_{2}$ ratio, deviation from the guideline without documented clinical indication, or no guideline at the bedside).

\section{Statistical Analysis}

Data were analyzed with SAS version 9.1 software (SAS Institute Inc, Cary, NC). Analysis of the 2 groups was on an intention-to-treat basis. All outcomes were assessed for normality and log transformed where appropriate. Univariate comparisons were performed with $\chi^{2}$ tests for equal proportion, Student $t$ tests for normally distributed outcomes, and Wilcoxon rank sum tests otherwise. Comparison of time to extubation was performed with a log-rank test, with results presented as Kaplan-Meier curves. Parametric data are presented as mean $\pm \mathrm{SD}$. Nonparametric data are expressed as median and interquartile range. Longitudinal analysis of continuously normally distributed outcomes (fluid balance and log of norepinephrine) were performed with mixed modeling (MIXED procedure), whereas longitudinal analysis of PGD grade was performed with ordinal mixed modeling (NL MIXED procedure). Longitudinal ordinal regression models for PGD were constructed with both a random intercept model and a random trend model. All mixed models were constructed with main effects for group and time and an interaction between group and time. Because group allocation was not randomly assigned, a propensity score for the intervention group was constructed to account for baseline imbalances and potential allocation bias, in accordance with Rubin, ${ }^{13}$ and was then included as a covariate in the longitudinal analyses. The propensity model was constructed by means of logistic regression with the following baseline variables fitted as predictors: recipient age, recipient sex, recipient smoking history, classification of recipient disease (obstructive, restrictive, or vascular), transplant type (double or single), duration of surgery, donor $\mathrm{PaO}_{2}$, ischemic time, baseline CVP on admission to ICU, and baseline PGD grade on admission to ICU. Longitudinal results have been presented as means for fluid balance and geometric means for norepinephrine. For ease of interpretation, PGD grades have also been presented as the mean PGD grade at each time point. Analyses were independent of the funding agency.

The baseline characteristics (donor, recipient, operative, and immediate postoperative factors on arrival in ICU) of the 2 groups are shown in Table 2. There was a greater proportion of patients with restrictive lung disease and a lower proportion of patients with obstructive lung disease in the 


\section{Lung Transplant Guideline Respiratory Management (while intubated)}

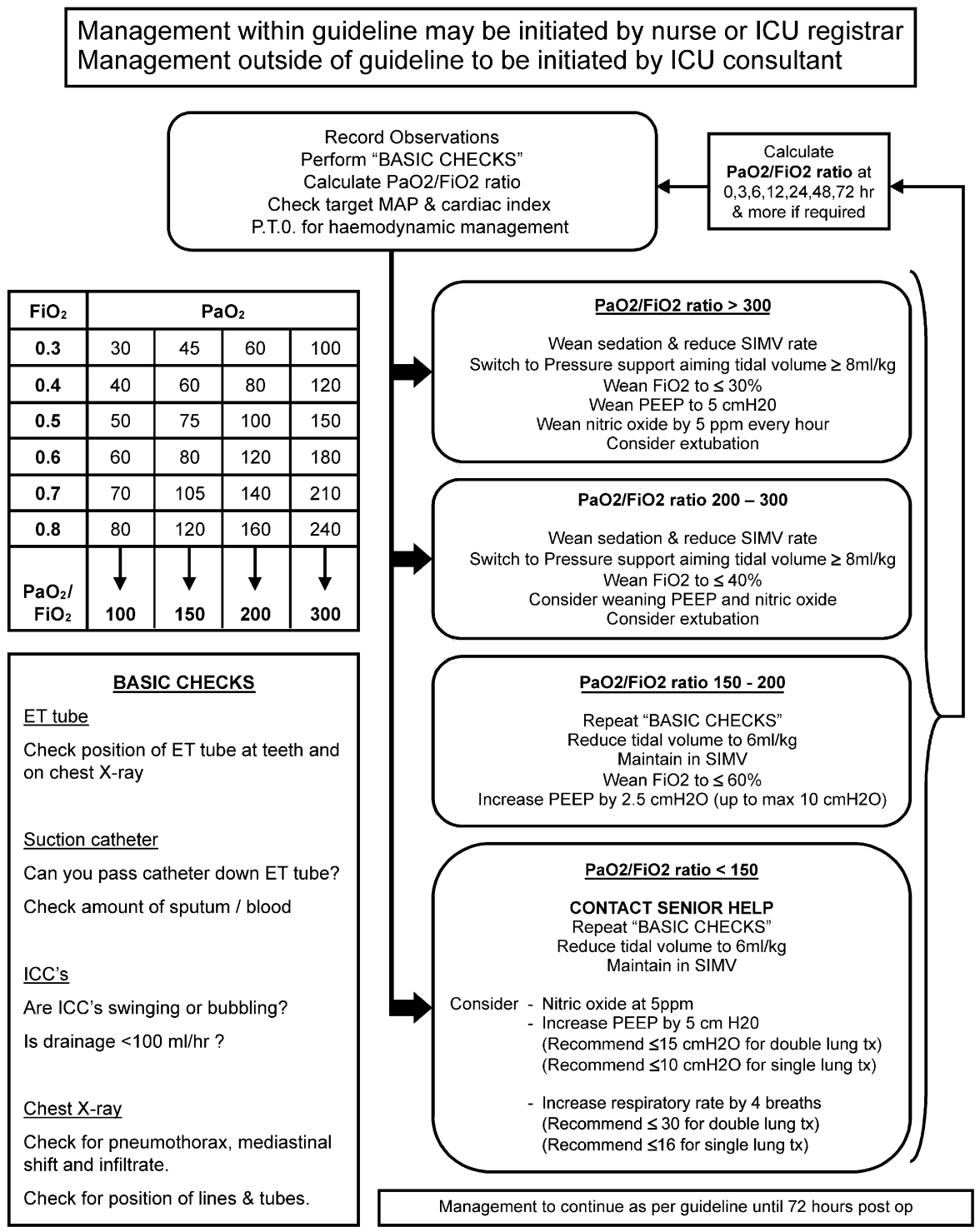

FIGURE 1. Lung transplant guideline, page 1. Respiratory management during intubation. $\mathrm{ICU}$, Intensive care unit; $\mathrm{PaO}_{2}$, arterial $\mathrm{PaO}_{2} ; \mathrm{FiO}_{2}$, fraction of inspired oxygen; $M A P$, mean arterial pressure; $P T O$, please turn over; $S I M V$, synchronized intermittent mandatory ventilation; $P E E P$, positive end-expiratory pressure; $E T$, endotracheal; ICC, intercostal catheter; $t x$, transplant.

postguideline group. On arrival in ICU from the operating room, a higher proportion of the postguideline group had CVPs greater than $7 \mathrm{~mm} \mathrm{Hg}$ (Table 2). Otherwise, there were no differences between the 2 groups in donor characteristics and no differences in the preoperative, operative, and initial ICU characteristics of the recipients.

\section{RESULTS}

\section{Primary Outcome}

The primary outcome was severity of PGD within the first 72 hours. Longitudinal ordinal regression models for PGD (constructed with both a random intercept model and a random trend model) confirmed a significant interaction between group and time $(P=.01$ and $P=.02$, respectively). This indicated that during the course of the 72 hours the 2 groups behaved differently, with the postguideline group tending toward a lower PGD grade (Figure 3).

\section{Secondary Outcomes}

There was a statistically significant group effect for cumulative fluid balance, with the postguideline group 


\section{Lung Transplant Guideline}

\section{Hemodynamic Management in first 72 hours}

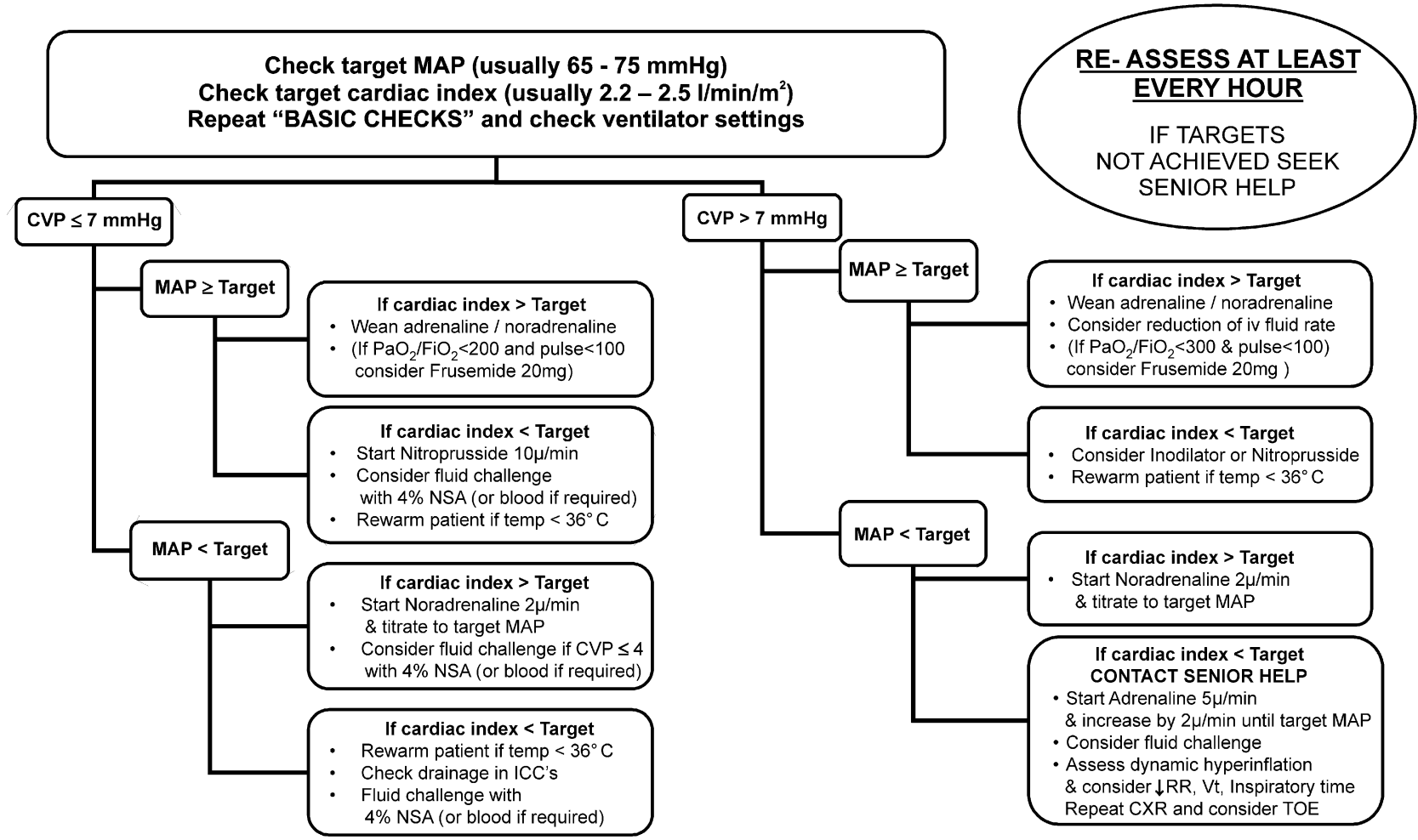

FIGURE 2. Lung transplant guideline, page 2. Hemodynamic management in first 72 hours. MAP, Mean arterial pressure; $C V P$, central venous pressure; $\mathrm{PaO}_{2}$, arterial $\mathrm{PaO}_{2} ; \mathrm{FiO}_{2}$, fraction of inspired oxygen; $N S A$, normal serum albumin; $I C C$, intercostal catheter; $R R$, respiratory rate; $V t$, tidal volume; $C X R$, chest radiograph; TOE, transesophageal echocardiography.

consistently lower during the 72-hour period $(P=.01)$. There was also a significant interaction between group and time $(P=.001)$, indicating that the difference in cumulative fluid balance between groups became larger as time progressed (Figure 4). Despite the lower cumulative fluid balances, norepinephrine dose requirements (Figure 5) were significantly lower in the postguideline group during the 72-hour period $(P=.007)$, although there was no evidence to suggest that the 2 groups behaved differently with time (interaction $P=.70$ ). There were no other differences in secondary outcomes (Table 3). Kaplan Meier analysis did not demonstrate any difference in the duration of mechanical ventilation between patients managed by the guideline and the preguideline group (Figure 6). Nonadherence to the guideline (as defined in advance by specific criteria) by the ICU staff was observed in 10 of 56 cases.

\section{DISCUSSION}

Our study demonstrated that care of lung transplant recipients according to a protocol is possible. The implementation of an evidence-based guideline was associated with a reduction in the severity of PGD within the first 72 hours after lung transplant. After the introduction of the guideline, there was less administration of intravenous fluid. This was not associated with any deterioration in renal function or increased requirement for vasopressor agents (indeed, norepinephrine requirements were lower in the postintervention group).

Our guideline provided the means to identify and manage PGD in the early postoperative period in an attempt to reduce the severity of PGD. Although the introduction of the guideline was associated with a reduction in severity of PGD, it is not clear whether this was a direct consequence of the guideline or whether other factors were more important in determining the severity of PGD. The occurrence of PGD has been shown to affect early outcomes and longterm survival after transplant. ${ }^{14}$ Further, more severe PGD on admission to ICU has been associated with an increased risk of bronchiolitis obliterans syndrome. ${ }^{15}$ The findings of these studies suggest that any intervention leading to reduction in the severity of PGD in the early postoperative period might, if applied widely enough, have important long-term clinical implications.

Although PGD is defined by the presence of a reduced $\mathrm{PaO}_{2} / \mathrm{FiO}_{2}$ ratio in the first 72 hours after transplant, ${ }^{3}$ it is 
TABLE 2. Baseline characteristics

\begin{tabular}{|c|c|c|c|}
\hline Characteristic & $\begin{array}{c}\text { Before } \\
\text { guidelines } \\
(\mathbf{n}=\mathbf{5 3}) \\
\end{array}$ & $\begin{array}{c}\text { After } \\
\text { guidelines } \\
(\mathbf{n}=\mathbf{5 6}) \\
\end{array}$ & $\begin{array}{c}P \\
\text { value } \\
\end{array}$ \\
\hline \multicolumn{4}{|l|}{ Recipient factors } \\
\hline Age $(y$, mean $\pm S D)$ & $46.6 \pm 14.1$ & $47.3 \pm 14.5$ & .799 \\
\hline Female $(\%)$ & $43 \%(23 / 53)$ & $54 \%(30 / 56)$ & .256 \\
\hline $\begin{array}{l}\text { Body mass } \\
\quad \text { index }\left(\mathrm{kg} / \mathrm{m}^{2}, \text { mean } \pm \mathrm{SD}\right)\end{array}$ & $22.3 \pm 4.0$ & $22.3 \pm 4.2$ & .985 \\
\hline $\begin{array}{l}\text { Vascular lung } \\
\quad \text { disease }(\%)\end{array}$ & $5.7 \%(3 / 53)$ & $5.5 \%(3 / 56)$ & $>.999$ \\
\hline $\begin{array}{l}\text { Obstructive lung } \\
\text { disease }(\%)\end{array}$ & $84.9 \%(45 / 53)$ & $63.6 \%(35 / 56)$ & .015 \\
\hline $\begin{array}{c}\text { Restrictive lung } \\
\text { disease }(\%)\end{array}$ & $9.4 \%(5 / 53)$ & $30.9 \%(17 / 56)$ & .008 \\
\hline \multicolumn{4}{|l|}{ Donor factors } \\
\hline Age $(y$, mean $\pm S D)$ & $37.0 \pm 13.2$ & $39.5 \pm 15.7$ & .374 \\
\hline $\begin{array}{l}\text { Arterial } \mathrm{Po}_{2}(\mathrm{~mm} \mathrm{Hg} \text {, mean } \\
\quad \pm \mathrm{SD})\end{array}$ & $446.4 \pm 110.4$ & $436.8 \pm 93.2$ & .640 \\
\hline Female $(\%)$ & $39.6 \%(21 / 53)$ & $46.4 \%(26 / 56)$ & .563 \\
\hline History of smoking $(\%)$ & $52.8 \%(28 / 53)$ & $55.4 \%(31 / 56)$ & .847 \\
\hline Inotropes $(\%)$ & $83.0 \%(44 / 53)$ & $83.9 \%(47 / 56)$ & .100 \\
\hline \multicolumn{4}{|l|}{ Operative factors } \\
\hline $\begin{array}{l}\text { Ischemic time } \\
\quad(\min , \text { mean } \pm \mathrm{SD})\end{array}$ & $359 \pm 20$ & $338 \pm 18$ & .440 \\
\hline $\begin{array}{l}\text { Duration of surgery } \\
\quad \text { (hours, mean } \pm \mathrm{SD})\end{array}$ & $6.0 \pm 1.5$ & $5.9 \pm 1.9$ & .634 \\
\hline Double-lung transplant $(\%)$ & $81.1 \%(43 / 53)$ & $76.4 \%(42 / 56)$ & .641 \\
\hline \multicolumn{4}{|c|}{ Initial findings on arrival in intensive care unit } \\
\hline $\begin{array}{l}\text { Primary graft } \\
\text { dysfunction grade } 2 \text { or } 3(\%)\end{array}$ & $56 \%(28 / 50)$ & $43 \%(24 / 56)$ & .180 \\
\hline $\begin{array}{l}\text { Central venous pressure } \\
\qquad(\mathrm{mm} \mathrm{Hg}, \text { median and IQR) }\end{array}$ & $4.5(5-10)$ & $7(2-6)$ & .001 \\
\hline $\begin{array}{l}\text { Central venous } \\
\text { pressure }>7 \mathrm{~mm} \mathrm{Hg}(\%)\end{array}$ & $20 \%(9 / 45)$ & $50 \%(28 / 56)$ & .002 \\
\hline $\begin{array}{l}\text { Mean arterial pressure } \\
\qquad(\mathrm{mm} \mathrm{Hg}, \text { mean } \pm \mathrm{SD})\end{array}$ & $68.9 \pm 13.5$ & $72.9 \pm 9.9$ & .322 \\
\hline $\begin{array}{l}\text { Cardiac index }\left(\mathrm{L} /\left[\mathrm{min} \cdot \mathrm{m}^{2}\right]\right. \\
\quad \text { mean } \pm \mathrm{SD})\end{array}$ & $3.1 \pm 1.2$ & $3.0 \pm 1.2$ & .623 \\
\hline $\begin{array}{l}\text { Norepinephrine } \\
\quad(\mu / \text { min, median and IQR })\end{array}$ & $4(2-6)$ & $3.75(2-6)$ & .731 \\
\hline Urea $(\mathrm{mmoL}$, mean $\pm \mathrm{SD})$ & $5.8 \pm 2.3$ & $6.3 \pm 2.6$ & .283 \\
\hline $\begin{array}{l}\text { Creatinine }(\mu \mathrm{moL} \text {, mean } \pm \\
\quad \mathrm{SD})\end{array}$ & $81 \pm 26$ & $77 \pm 32$ & .496 \\
\hline
\end{tabular}

$I Q R$, Interquartile range.

unknown whether there are time points within this period that are more clinically relevant. Oto and coworkers ${ }^{16}$ suggested that the $\mathrm{PaO}_{2} / \mathrm{FiO}_{2}$ ratio as early as 6 or 12 hours after transplant predicts length of ventilation and stay in ICU. Prekker and colleagues ${ }^{17}$ have suggested that the grade of PGD at 48 hours provides the clearest differentiation of 90-day mortality. Although the severity of PGD during the first 72 hours after lung transplant was indeed different after the introduction of the guideline, mortalities were identical in the groups (Table 3). Mortalities associated with lung transplant at The Alfred Hospital (2004-2006) were 3.5\% at 3 months and $7 \%$ at 1 year, which compare favorably with respective figures of $7.8 \%$ and $15.9 \%$ reported for the year 2004 from the United Network for Organ Sharing database. ${ }^{18}$ It may be that other factors are responsible for the low mortality at our institution and that these factors were not controlled for in our trial and are completely unrelated to the guideline. It is possible, however, that a guideline such as ours may provide a template to standardize postoperative care and thus study therapeutic interventions targeted to reduce the incidence of PGD, which might translate into more clinically relevant outcomes such as duration of ventilation, stay in ICU, and ultimately mortality.

For an evidence-based guideline to be effective in changing the process and improving the outcomes of care, multidisciplinary team members should be involved in the development, implementation, and ongoing updating of the guideline. ${ }^{19,20}$ Our guideline adhered to these principles and was based on the best available evidence at the time. It will continue to be reviewed and modified to incorporate new evidence as needed. ${ }^{21}$ Indeed, it was noted on a few occasions that although respiratory and hemodynamic parameters were acceptable to allow discontinuation of mechanical ventilation, extubation was delayed because of inadequate analgesia. The next revised version will include a pain management strategy.

Adherence to the guideline was acceptable, and its implementation was well received by both medical and nursing staff. The preguideline and postguideline groups were well matched in most areas. The postguideline group did have higher CVPs on admission to ICU and a higher proportion of patients with restrictive lung disease. These 2 factors might be considered to represent increased risks for difficult postoperative course and higher likelihood of $\mathrm{PGD}^{3,4,7}$; in fact, however, the opposite was seen.

There are a number of limitations of our study. First, this was not a randomized, controlled trial, and it is possible that factors not accounted for in this study may have led to the changes observed between the preguideline and postguideline groups. Management of these patients may have improved during the duration of the study as a result of the subtly progressive acquisition of knowledge and skills by clinicians. Indeed, despite the effort taken to ensure that all relevant information was included, recorded, and analyzed, it is possible that incomplete analysis of retrospective data may have biased our results. Second, it is possible that the trend toward a higher incidence of PGD on arrival in ICU seen in the historical cohort was indeed a reflection that the group was more likely to have PGD at other time points after transplant, although we attempted to adjust for this possibility in our analysis. Third, although creation of a protocol for respiratory management to introduce small tidal volumes and to seek senior help for patients with the worst oxygenation parameters is likely to have helped minimize lung 


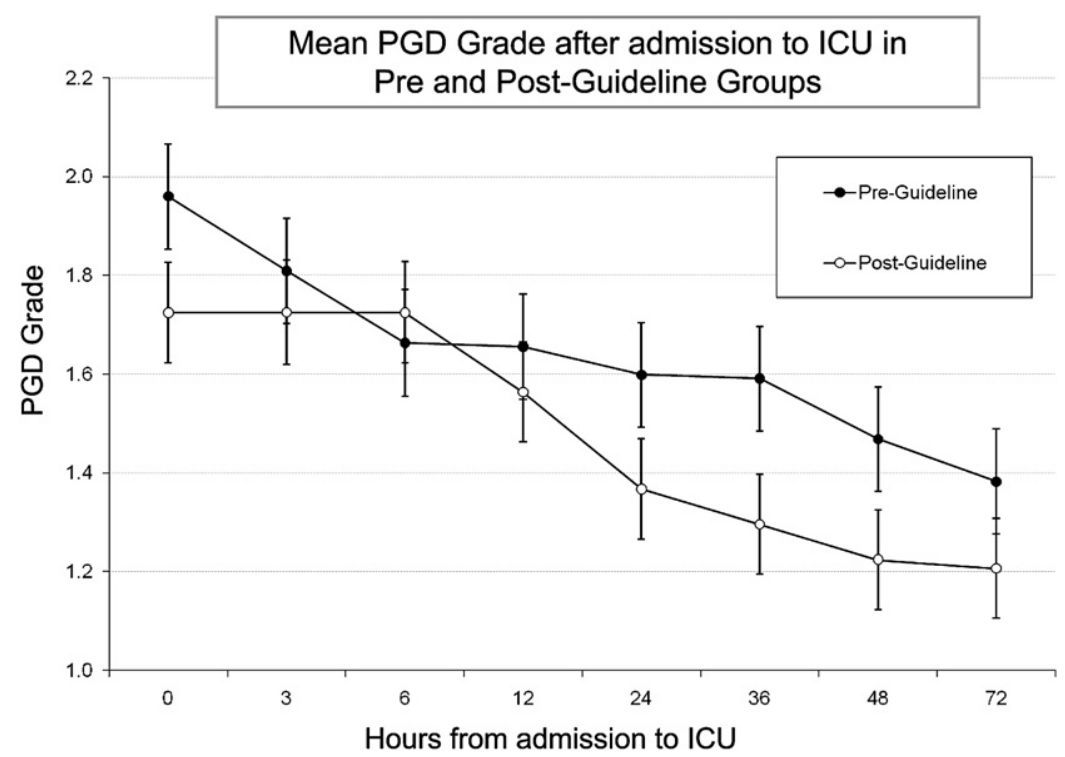

FIGURE 3. Mean primary graft dysfunction $(P G D)$ grade after admission to intensive care unit $(I C U)$ in preguideline and postguideline groups. Mean primary graft dysfunction grade (with SEs indicated by error bars) at time points after admission to intensive care unit for preguideline and postguideline groups. Longitudinal ordinal regression models for primary graft dysfunction (constructed with both random intercept model and random trend model) confirmed significant interaction between group and time $(P=.01$ and $P=.02$, respectively).

injury, it is possible that some patients still received injurious ventilation with high airway pressures. Fourth, it is possible that the lower use of vasopressors and less positive fluid balance were consequences of more aggressive fluid resuscitation in the operating room. This possibility is sup- ported by the finding that this group had higher CVPs on admission to ICU. Fifth, it is important to consider that this study involved more than just the implementation of a simple flowchart by the bedside. It is possible that any changes in outcome were equally due to the education and

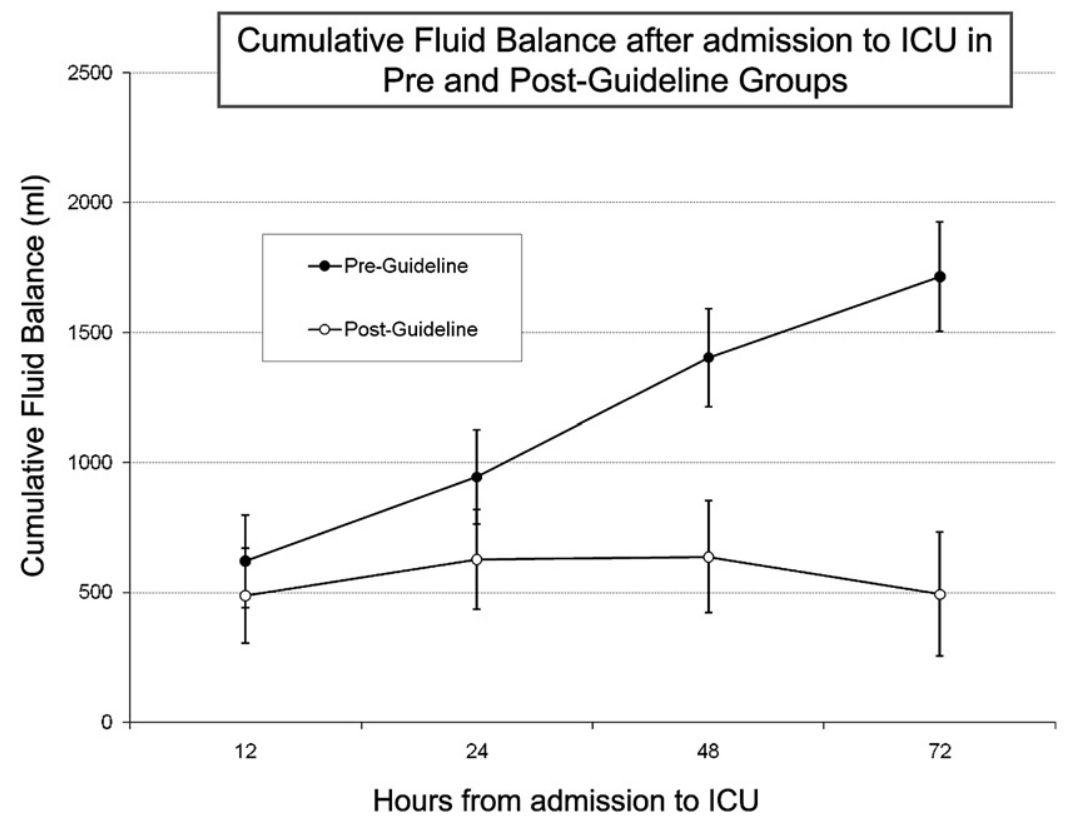

FIGURE 4. Mean cumulative fluid balance to 72 hours from intensive care unit (ICU) admission. Mean cumulative fluid balance (with SEs indicated by error bars) at time points after admission to intensive care unit for preguideline and postguideline groups. Longitudinal analysis demonstrated statistically significant group effect, with postguideline group consistently lower during 72-hour period $(P=.01)$. There was also significant interaction between group and time $(P=.001)$, indicating that difference in cumulative fluid balance between groups became larger as time progressed. 


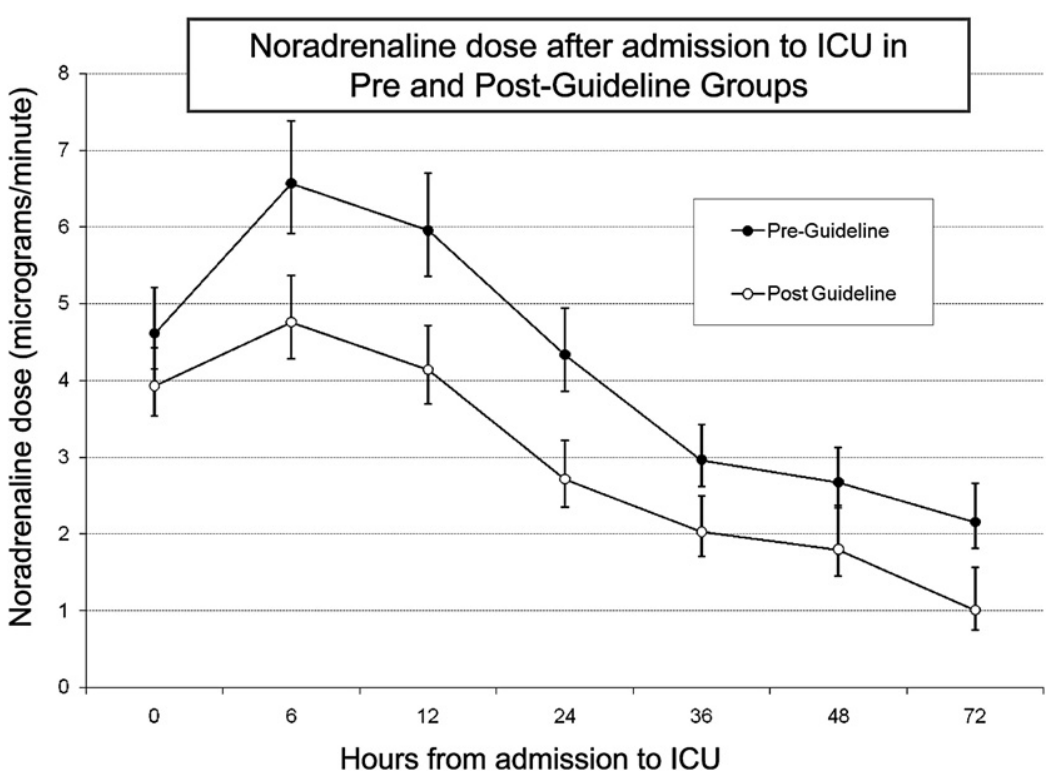

FIGURE 5. Norepinephrine (Noradrenaline) dose after admission to intensive care unit (ICU) in preguideline and postguideline groups. Norepinephrine dose (geometric mean with SEs indicated by error bars) at time points after admission to intensive care unit for preguideline and postguideline groups. Longitudinal analysis indicated norepinephrine dose requirements were significantly lower in postguideline group during 72 -hour period $(P=.007)$. There was no evidence to suggest that groups behaved differently with time (interaction $P=.70$ ).

support provided to clinicians by the transplant and research team. Sixth, it unknown whether wider application of guidelines such as ours might translate into changes in clinically important outcomes, such as duration of ventilation, stay, and mortality, for larger groups of patients.

\section{CONCLUSIONS}

In this preinterventional and postinterventional study, we investigated the impact of implementing an evidence-based guideline to manage transplant recipients' hemodynamic and respiratory statuses in the first 72 hours, with the aim of minimizing the severity of PGD. Postoperative care of lung transplant patients according to a protocol was possible, did not appear to be associated with adverse effects (renal function was unchanged; fluid and vasopressor administration were lower), and was associated with a reduction in severity of PGD. Although there was no reduction in duration of mechanical ventilation or mortality, our results suggest that further studies of protocol-based care in larger samples are warranted. When combined with the recently refined PGD grading system, ${ }^{3,4}$ these guidelines provide a practical tool that allows safe standardization of post-operative lung transplant management. In turn, this may facilitate multicenter studies aimed at assessing novel strategies aimed at minimizing the significant adverse effects of PGD.

We thank the clinical staff of the Alfred Hospital intensive care unit for supporting this research.

TABLE 3. Secondary outcomes

\begin{tabular}{|c|c|c|c|}
\hline Outcome & Before guidelines $(n=53)$ & After guidelines $(\mathbf{n}=\mathbf{5 6})$ & $P$ value \\
\hline $\begin{array}{l}\text { Duration of mechanical ventilation ( } h \text {, median and } \\
\text { IQR) }\end{array}$ & $22(9-54)$ & $20(13-45)$ & .821 \\
\hline ICU stay ( $d$, median and IQR) & $3.1(1.9-7.1)$ & $3.6(2.1-5.0)$ & .912 \\
\hline Inhaled nitric oxide $(\%)$ & $24.5 \%(13 / 53)$ & $16.1 \%(9 / 56)$ & .342 \\
\hline Readmission to ICU (\%) & $9.4 \%(5 / 53)$ & $10.7 \%(6 / 56)$ & $>.999$ \\
\hline Death in ICU $(\%)$ & $1.9 \%(1 / 53)$ & $1.9 \%(1 / 56)$ & $>.999$ \\
\hline Death in hospital $(\%)$ & $1.9 \%(1 / 53)$ & $1.9 \%(1 / 56)$ & $>.999$ \\
\hline Urea at $72 \mathrm{~h}(\mathrm{mmoL}$, mean $\pm \mathrm{SD})$ & $9.6 \pm 5.4$ & $9.5 \pm 5.8$ & .913 \\
\hline Urea at $1 \mathrm{wk}(\mathrm{mmoL}$, mean $\pm \mathrm{SD})$ & $8.8 \pm 6.3$ & $8.5 \pm 4.6$ & .239 \\
\hline Creatinine at $72 \mathrm{~h}(\mu \mathrm{moL}$, mean $\pm \mathrm{SD})$ & $81 \pm 38$ & $73 \pm 29$ & .781 \\
\hline Creatinine at $1 \mathrm{wk}(\mu \mathrm{moL}$, mean $\pm \mathrm{SD})$ & $69 \pm 26$ & $67 \pm 19$ & .630 \\
\hline
\end{tabular}

$I Q R$, Interquartile range; $I C U$, intensive care unit. 


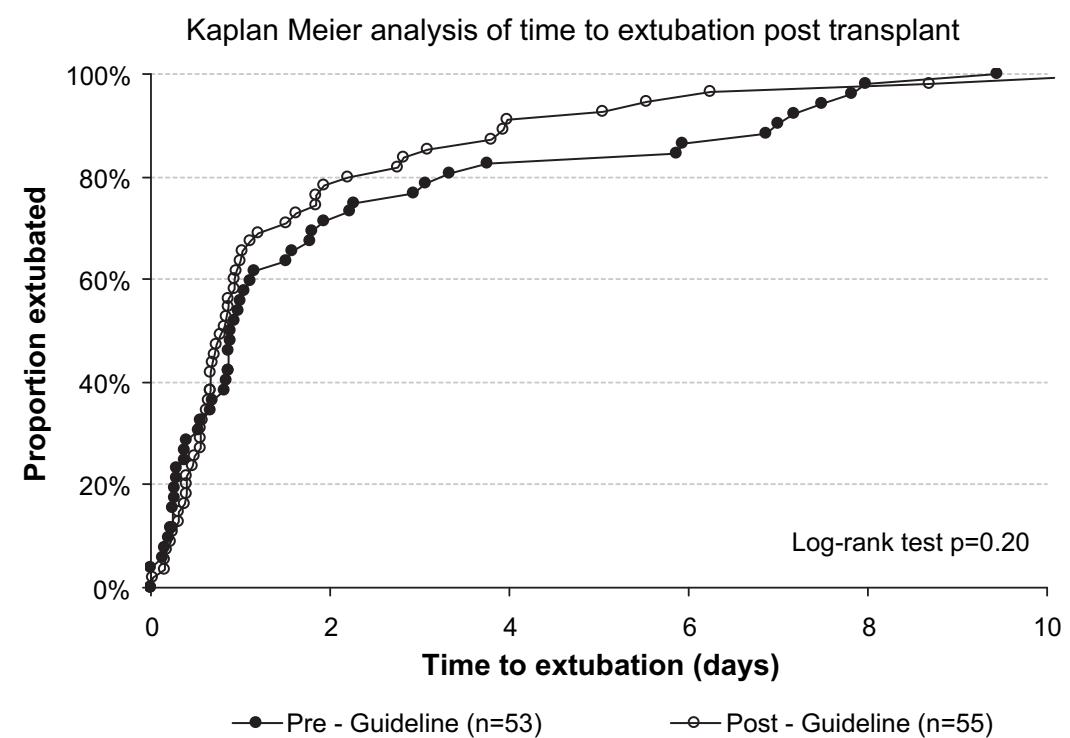

FIGURE 6. Kaplan-Meier analysis of time to extubation after transplant.

\section{References}

1. Bittner HB, Binner C, Dahlberg P, Mohr FW. Reducing ischemia-reperfusion injury in clinical lung transplantation. Transplant Proc. 2007;39:489-92.

2. Christie JD, Kotloff RM, Ahya VN, Tino G, Pochettino A, Gaughan C, et al. The effect of primary graft dysfunction on survival after lung transplantation. Am J Respir Crit Care Med. 2005;171:1312-6.

3. Christie JD, Carby M, Bag R, Corris P, Hertz M, Weill D. Report of the ISHLT Working Group on Primary Lung Graft Dysfunction part II: definition. A consensus statement of the International Society for Heart and Lung Transplantation. $J$ Heart Lung Transplant. 2005;24:1454-9.

4. Oto T, Levvey BJ, Snell GI. potential refinements of The International Society for Heart And Lung Transplantation primary graft dysfunction grading system. $J$ Heart Lung Transplant. 2007;26:431-6.

5. Ventilation with lower tidal volumes as compared with traditional tidal volumes for acute lung injury and the acute respiratory. The Acute Respiratory Distress Syndrome Network. N Engl J Med. 2000;342:1301-8.

6. Shargall Y, Guenther G, Ahya VN, Ardehali A, Singhal A, Keshavjee S, et al. Report of the ISHLT Working Group on Primary Lung Graft Dysfunction part VI: treatment. J Heart Lung Transplant. 2005;24:1489-500.

7. Pilcher DV, Scheinkestel CD, Snell GI, Davey-Quinn A, Bailey MJ, Williams TJ. High central venous pressure is associated with prolonged mechanical ventilation and increased mortality after lung transplantation. $J$ Thorac Cardiovasc Surg. 2005;129:912-8.

8. Esmore DS, Brown R, Buckland M, Briganti EM, Fetherston GJ, Rabinov M, et al. Techniques and results in bilateral sequential single lung transplantation. The National Heart \& Lung Replacement Service. J Card Surg. 1994;9:1-14.

9. Gabbay E, Williams TJ, Griffiths AP, Macfarlane LM, Kotsimbos TC, Esmore DS, et al. Maximizing the utilization of donor organs offered for lung transplantation. Am J Respir Crit Care Med. 1999;160:265-71.

10. Oto T, Rabinov M, Griffiths A, Whitford H, Levvey B, Esmore D, et al. Unexpected donor pulmonary embolism affects early outcomes after lung transplantation: a major mechanism of primary graft failure? J Thorac Cardiovasc Surg. 2005;130:1441-6.
11. Orens JB, Boehler A, de Perrot M, Estenne M, Glanville AR, Keshavjee S, et al. A review of lung transplant donor acceptability criteria. J Heart Lung Transplant. 2003;22:1183-200

12. Snell GI, Westall GP. Immunosuppression for lung transplantation: evidence to date. Drugs. 2007;67:1531-9.

13. Rubin DB. The design versus the analysis of observational studies for causal ef fects: parallels with the design of randomized trials. Stat Med. 2007;26:20-36.

14. Whitson BA, Prekker ME, Herrington CS, Whelan TP, Radosevich DM, Hertz MI, et al. Primary graft dysfunction and long-term pulmonary function after lung transplantation. J Heart Lung Transplant. 2007;26:1004-11.

15. Daud SA, Yusen RD, Meyers BF, Chakinala MM, Walter MJ, Aloush AA, et al. Impact of immediate primary lung allograft dysfunction on bronchiolitis obliterans syndrome. Am J Respir Crit Care Med. 2007;175:507-13.

16. Oto T, Levvey B, Pilcher DV, Bailey MJ, Snell GI. Evaluation of the oxygenation ratio in the definition of early graft dysfunction post lung transplantation. J Thorac Cardiovasc Surg. 2005;130:180-6.

17. Prekker ME, Nath DS, Walker AR, Johnson AC, Hertz MI, Herrington CS, et al Validation of the proposed International Society for Heart and Lung Transplantation grading system for primary graft dysfunction after lung transplantation. $J$ Heart Lung Transplant. 2006;25:371-8.

18. Department of Health and Human Services, Health Resources and Services Ad ministration, Healthcare Systems Bureau, Division of Transplantation; United Network for Organ Sharing; University Renal Research and Education Association. Annual report of the U.S. Organ Procurement and Transplantation Network and the Scientific Registry of Transplant Recipients: transplant data 1994-2006. Rockville (MD): The Department; 2006.

19. Kitson AL. Approaches used to implement research findings into nursing practice: report of a study tour to Australia and New Zealand. Int J Nurs Pract. 2001;7: 392-405.

20. Thomas L, Cullum N, McColl E, Rousseau N, Soutter J, Steen N. Guidelines in professions allied to medicine. Cochrane Database Syst Rev. 2000 (2):CD000349.

21. National Health and Medical Research Council. How to use the evidence: assessment and application of scientific evidence. Canberra: Commonwealth of Australia; 2000 